\title{
Variation in genome size and karyotype among closely related aphid parasitoids (Hymenoptera, Aphelinidae)
}

\author{
Vladimir E. Gokhman', Kristen L. Kuhn², James B. Woolley³, Keith R. Hopper² \\ I Botanical Garden, Moscow State University, Moscow, Russia 2 Beneficial Insects Introduction Research Unit, \\ ARS-USDA, 501 South Chapel Street, Newark, Delaware, United States of America 3 Department of Ento- \\ mology, Texas A\&M University, College Station, Texas, United States of America
}

Corresponding author: Keith R. Hopper (Keith.Hopper@ars.usda.gov)

Academic editor: M. Bressa | Received 25 October 2016 | Accepted 4 January 2017 | Published 23 February 2017

http://zoobank.org/7D29D113-1F00-4445-80A2-6A2B3B4D30C1

Citation: Gokhman VE, Kuhn KL, Woolley JB, Hopper KR (2017) Variation in genome size and karyotype among closely related aphid parasitoids (Hymenoptera, Aphelinidae). Comparative Cytogenetics 11(1): 97-117. https://doi. org/10.3897/CompCytogen.v11i1.10872

\begin{abstract}
Genome sizes were measured and determined for the karyotypes of nine species of aphid parasitoids in the genus Aphelinus Dalman,1820. Large differences in genome size and karyotype were found between Aphelinus species, which is surprising given the similarity in their morphology and life history. Genome sizes estimated from flow cytometry were larger for species in the A. mali (Haldeman, 1851) complex than those for the species in the $A$. daucicola Kurdjumov, 1913 and $A$. varipes (Förster,1841) complexes. Haploid karyotypes of the $A$. daucicola and $A$. mali complexes comprised five metacentric chromosomes of similar size, whereas those of the $A$. varipes complex had four chromosomes, including a larger and a smaller metacentric chromosome and two small acrocentric chromosomes or a large metacentric and three smaller acrocentric chromosomes. Total lengths of female haploid chromosome sets correlated with genome sizes estimated from flow cytometry. Phylogenetic analysis of karyotypic variation revealed a chromosomal fusion together with pericentric inversions in the common ancestor of the $A$. varipes complex and further pericentric inversions in the clade comprising Aphelinus kurdjumovi Mercet, 1930 and Aphelinus hordei Kurdjumov, 1913. Fluorescence in situ hybridization with a 28 S ribosomal DNA probe revealed a single site on chromosomes of the haploid karyotype of Aphelinus coreae Hopper \& Woolley, 2012. The differences in genome size and total chromosome length between species complexes matched the phylogenetic divergence between them.
\end{abstract}

\section{Keywords}

Aphelinidae, Aphelinus, parasitoid, genome size, flow cytometry, karyotype

Copyright Vladimir E. Gokhman et al. This is an open access article distributed under the terms of the Creative Commons Attribution License (CC BY 4.0), which permits unrestricted use, distribution, and reproduction in any medium, provided the original author and source are credited. 


\section{Introduction}

Genome size estimates and karyotypic studies provide data for comparative research at various taxonomic levels and allow evaluation of phylogenetic associations (Gokhman 2009, Hanrahan and Johnston 2011, Lopes et al. 2009). The completeness of genome assemblies can be difficult to assess, and independent estimates of genome size can aid in the assessment of completeness of genome assemblies (Gregory et al. 2013). Flow cytometry and Feulgen densitometry have been used to accurately measure genome size, and both methods have been extensively validated and various sources of error have been minimized through best-practice protocols (Gregory et al. 2013, Hare and Johnston 2011). Karyotypes can further help in assessing genetic linkage maps, and thus aid in mapping quantitative trait loci (Gokhman and Kuznetsova 2006). To visualize karyotypic features, various techniques of conventional and differential staining of chromosomes have been used, including fluorescence in situ hybridization (FISH), which allows physical mapping of DNA sequences onto chromosomes (Gadau et al. 2014, Macgregor and Varley 1988). Increasing the numbers of genome size estimates and karyotypes across the tree of life provides resources for the advancement of evolutionary genomics (Jacobson et al. 2013, Sharakhova et al. 2014). Furthermore, both flow cytometry and karyotypes can be used to detect cryptic species (Baur et al. 2014, Vergilino et al. 2012).

Genome size estimates have been published for more than 13,000 species of animals and plants (Animal Genome Size Database, http://www.genomesize.com; Plant DNA C-values Database, http://data.kew.org/cvalues; accessed 29 August 2014). There are currently 930 estimates of insect genome size in the Animal Genome Size Database, 152 of which are for species of Hymenoptera, and these genome sizes range from 98 to $1115 \mathrm{Mb}$. Genome size is usually considered constant within species, and limited intraspecific variation is a standard assumption in measurement and comparison of genome sizes. However, genome size can vary widely between closely related species (Gregory and Johnston 2008) and even within species (Biemont 2008, Bosco et al. 2007). The most common source of inter- and intraspecific genome size variation is differing amounts of repetitive DNA (Biemont 2008, Bosco et al. 2007). Differences in chromosome size can result from differences in heterochromatin content and amount of repetitive DNA in euchromatin, and differences in both chromosome size and number can result from fissions and fusions (Gokhman 2009, White 1973). Chromosome numbers and other karyotypic features have been published for about 70,000 species of plants and animals (Rice et al. 2014, White 1973; Tree of Sex: A database of sexual systems, doi: 10.1038/sdata.2014.15), including more than 1,500 species of Hymenoptera, whose haploid chromosome numbers range from 1 to 60 (Gokhman 2009, Ross et al. 2015).

Here we report genome size estimates and karyotypes for males and females in nine species of Aphelinus Dalman, 1820 (Hymenoptera: Chalcidoidea: Aphelinidae) all of which are parasitoids of aphids. Parasitoids are free-living as adults, but are 
parasitic as larvae, and represent one of the most species-rich groups of insects, constituting more than 10\% of all described insect species (Eggleton and Belshaw 1992, Heraty et al. 2007). Parasitoids are important regulators of arthropod populations, including major agricultural pests (Godfray 1994). The genus Aphelinus comprises more than 90 recognized species (Hopper et al. 2012; Universal Chalcidoidea Database, www.nhm.ac.uk/entomology/chalcidoids/index.html, accessed 10 October 2016). Within Aphelinus, several complexes of closely related species provide excellent opportunities to explore genetic differentiation, speciation, and the evolution of reproductive compatibility, host use, and morphology (Heraty et al. 2007, Hopper et al. 2012). We studied species in three complexes of Aphelinus: (1) five species in the $A$. varipes (Förster, 1841) complex from throughout Eurasia; (2) three species in the $A$. mali (Haldeman, 1851) complex from eastern Asia; (3) one species in the A. daucicola Kurdjumov, 1913 complex from North America. The A. varipes complex comprises 12 described species (Förster 1841, Hayat 1972, 1994, Hayat and Fatima 1992, Howard 1908, Kurdjumov 1913, Nikol'skaya and Yasnosh 1966, Pan 1992, Yasnosh 1963). The monophyly of the $A$. varipes complex is well supported by a combination of morphological and genetic characters (Heraty et al. 2007). However, some species within the complex show little morphological divergence, making identification difficult. The $A$. mali complex comprises 14 recognized species, some of which also show little morphological divergence (Ashmead 1888, Evans et al. 1995, Gahan 1924, Girault 1913, Haldeman 1851, Hayat 1998, Hopper et al. 2012, Prinsloo and Neser 1994, Timberlake 1924, Yasnosh 1963, Zehavi and Rosen 1988). The A. daucicola species complex comprises three species that differ from the members of the $A$. mali complex in several traits (Hopper et al. 2012). Using flow cytometry, we estimated the genome sizes of species in these complexes. We also made and examined chromosomal preparations to determine their karyotypes. We found consistent differences in genome size between complexes, and these differences correlated with differences in relative sizes estimated from karyotypes. We detected chromosomal rearrangements as well as karyotypic synapomorphies.

\section{Materials and methods}

\section{Specimens}

The parasitoid species studied, the sources of the colonies, and the permit and voucher numbers are listed in Table 1. These colonies were reared on aphids at the USDA-ARS, Beneficial Insect Introductions Research Unit, in Newark, Delaware, USA. Vouchers for these populations are maintained at $-20{ }^{\circ} \mathrm{C}$ in $100 \%$ molecular grade ethanol at the Beneficial Insect Introduction Research Unit, Newark, Delaware. Females of the yellow-white strain of Drosophila melanogaster (Meigen, 1830) (stock number 1495, obtained from the Bloomington Drosophila Stock Center at 
Table I. The nine Aphelinus species studied, the year and country of their collection, permit and voucher numbers.

\begin{tabular}{c|l|c|c|c|c}
\hline $\begin{array}{c}\text { Species } \\
\text { complex }\end{array}$ & \multicolumn{1}{|c|}{ Species } & Authority & Year & Country & Permit and voucher \\
\hline \multirow{4}{*}{ A. varipes } & A. atriplicis & Kurdjumov, 1913 & 2000 & Georgia & P526P-15-04274, VGg00_Dn \\
\cline { 2 - 6 } & A. varipes & (Förster, 1841) & 2009 & France & P526P-13-02503, VFr09_Rp \\
\cline { 2 - 6 } & A. certus & Yasnosh, 1963 & 2001 & Japan & P526P-01-53096, VJp01_TU \\
\cline { 2 - 6 } & A. kurdjumovi & Mercet, 1930 & 2000 & Georgia & P526P-13-02503, VGg00_Rp \\
\cline { 2 - 6 } & A. hordei & Kurdjumov, 1913 & 2011 & France & P526P-15-04274, VFr11_Dn \\
\hline A. daucicola & A. daucicola & Kurdjumov, 1913 & 2013 & USA & P526P-15-04274, DUSA12_UD \\
\hline \multirow{4}{*}{ A. mali } & A. glycinis & Hopper et Woolley, 2012 & 2007 & China & P526P-08-02142, MKor09_M \\
\cline { 2 - 6 } & A. coreae & Hopper et Woolley, 2012 & 2009 & Korea & P526P-01-72318, MCh04_Bj \\
\cline { 2 - 6 } & A. rhamni & Hopper et Woolley, 2012 & 2005 & China & P526P-01-53096, MCh05_Bj \\
\hline
\end{tabular}

Indiana University, http://flystocks.bio.indiana.edu) were used as internal controls for flow cytometry. All institutional and national guidelines for the care and use of laboratory animals were followed.

\section{Flow cytometry}

Live Aphelinus were sexed, flash frozen in liquid nitrogen, and stored at $-80^{\circ} \mathrm{C}$. To estimate genome sizes, we used the flow cytometry protocol described by Hanrahan and Johnston (2011) and Hare and Johnston (2011). We dissected heads from both males and females of the Aphelinus species in cold Galbraith buffer (Galbraith et al. 1983). Heads of female $D$. melanogaster were used as internal standards $(1 \mathrm{C}=175 \mathrm{Mb}$ or 0.17 pg). To release the nuclei from cells, heads from 15 female Aphelinus and one female Drosophila Fallén, 1823 for each replicate were ground together in one milliliter of cold Galbraith buffer using 15 strokes of the "A" pestle in a 2-ml Kontes Dounce tissue grinder. As with other Hymenoptera, Aphelinus species have haplodiploid sex determination, with males coming from unfertilized eggs and females from fertilized eggs. Thus males carried half as much DNA per cell as females, which made male genome sizes too close to that of $D$. melanogaster. Thus when processed the heads of 15 males per replicate as described above, we included the heads from 15 females of the same parasitoid species as internal standards. The samples were passed through a 35 micron filter and then stained with 40 parts per million of propidium iodide in the dark for 3-5 hours at $4^{\circ} \mathrm{C}$. Samples were analyzed with laser excitation at $488 \mathrm{~nm}$ on a Becton Dickinson FACSCalibur Flow Cytometer (BD Biosciences, San Jose, CA, USA) at CTCR Core Facility, University of Delaware. Red fluorescence from the propidium iodide was detected using an FL2 filter. Three to six replicates were measured for females and males of each species.

The haploid content of DNA in megabases $(\mathrm{Mb})$ was calculated for each Aphelinus sample from the ratio of mean fluorescence of the sample to mean fluorescence of the 
standard times the genome size of the standard. We report genome size estimates in megabases, but also give estimates in picograms (pg) calculated by dividing the amount of DNA in $\mathrm{Mb}$ by the standard $1 \mathrm{C}$ value of $978 \mathrm{Mb}$.

\section{Karyotypes}

Chromosome preparations were made from cerebral ganglia of prepupae using a modified version of the technique in Imai et al. (1988). Wasps were dissected in $0.5 \%$ hypotonic sodium citrate solution containing $0.005 \%$ colchicine, and the tissues were incubated in fresh solution for -30 minutes at room temperature. The material was transferred to a pre-cleaned microscope slide using a Pasteur pipette and gently flushed with Fixative I (glacial acetic acid: absolute ethanol: distilled water 3:3:4). Tissues were disrupted in an additional drop of Fixative I using dissecting needles. Another drop of Fixative II (glacial acetic acid: absolute ethanol 1:1) was then applied to the center of the area and blotted off the edges of the slide. The slide was air dried for $\sim 30$ minutes at room temperature. For conventional staining, preparations were stained with freshly prepared 3\% Giemsa solution in $0.05 \mathrm{M}$ Sørensen's phosphate buffer $\left(\mathrm{Na}_{2} \mathrm{HPO}_{4}+\right.$ $\mathrm{KH}_{2} \mathrm{PO}_{4}, \mathrm{pH}$ 6.8). Mitotic divisions were studied and photographed using an optic microscope Zeiss Axioskop 40 FL fitted with a digital camera AxioCam MRc (Carl Zeiss, Oberkochen, Germany). To obtain karyograms, the resulting images were processed with image analysis programs: Zeiss AxioVision version 3.1 and Adobe Photoshop version 8.0. Mitotic chromosomes were measured for 5-19 cells in 1-6 wasps per species using Adobe Photoshop. We report total length $(\mu \mathrm{m})$ of all chromosomes in each karyotype for males and females; for diploid sets, we divided total length by two to make the values comparable to haploid sets. We also report relative lengths (RL: $100 \times$ length of each chromosome divided by total length of the set) and centromeric indices (CI: $100 \times$ length of shorter arm divided by total length of a chromosome) for females of each species. Chromosomes were classified into metacentric (M) or acrocentric (A) according to the guidelines in Levan et al. (1964).

\section{Fluorescence in situ hybridization}

A custom biotinylated fragment from the $28 \mathrm{~S} \mathrm{rDNA}$ gene was used to probe $A$. coreae chromosomes with fluorescence in situ hybridization (FISH). To prepare the probe, we extracted DNA from -50 adult parasitoids using a Qiagen DNeasy Blood and Tissue Kit (Qiagen, Valencia, CA, USA). From this DNA, we amplified a -650 nt fragment of the $28 \mathrm{~S} \mathrm{rDNA}$ gene using the following primers and PCR protocol: reaction mix - 5 $\mu \mathrm{l}$ NEB PCR buffer and $0.5 \mu \mathrm{l} \mathrm{Taq}$ polymerase (New England Biolabs, Ipswich, MA, USA), $4 \mu$ each of $2.5 \mathrm{mM}$ dATP, dCTP, dGTP, $4 \mu \mathrm{l} 0.25 \mathrm{mM}$ dTTP plus $1 \mu \mathrm{l} 1 \mathrm{mM}$ biotinylated-11-dUTP, $1 \mu \mathrm{l} 10 \mu \mathrm{M}$ forward primer (5'-cgt gtt gct tga tag tgc agc) and 1 $\mu \mathrm{l} 10 \mu \mathrm{M}$ reverse primer (5'-tca aga cgg gtc ctg aaa gt), $4 \mu \mathrm{l}$ genomic DNA (50 ng/ $\mu \mathrm{l})$, 
$21.5 \mu \mathrm{l}$ ultrapure $\mathrm{H}_{2} \mathrm{O}$; cycling -3 min at $95^{\circ} \mathrm{C}$, then 35 cycles $95^{\circ} \mathrm{C}$ for $30 \mathrm{sec}, 55^{\circ} \mathrm{C}$ for $30 \mathrm{sec}$, and $72^{\circ} \mathrm{C}$ for $60 \mathrm{sec}$, and a final extension at $72{ }^{\circ} \mathrm{C}$ for $3 \mathrm{~min}$. Unincorporated dNTPs, primers, and other unwanted components were removed from the PCR product using precipitation with sodium acetate and ethanol, and the resulting pellet was resuspended in $50 \mu \mathrm{l}$ ultrapure $\mathrm{H}_{2} \mathrm{O}$, yielding a solution of probe at $300 \mathrm{ng} / \mu \mathrm{l}$.

Chromosomes were prepared for probing using the protocol described above for karyotyping. To probe the chromosomes, a protocol modified from Matsumoto et al. (2002) was used. Chromosomes were baked onto slides at $65^{\circ} \mathrm{C}$ and UV crosslinked in a Spectrolinker XL-1000 UV Crosslinker (Spectronics, Westbury, NY, USA) twice at $120 \mathrm{~mJ} / \mathrm{cm}^{2}$. The slides were treated with RNase A, dehydrated with ethanol, denatured in formamide, and then dehydrated again with ethanol. The slides were then treated with proteinase $\mathrm{K}$ and dehydrated a third time with ethanol. Hybridization solution was prepared from the biotinylated probe $(7 \mu \mathrm{g}$ in $23 \mu \mathrm{l})$, formamide $(90 \mu \mathrm{l})$, $30 \%$ dextran sulfate solution $(60 \mu \mathrm{l}), 10 \mathrm{mg} / \mathrm{ml}$ salmon sperm DNA $(5 \mu \mathrm{l})$, and $20 \mathrm{x}$ SSC $(22 \mu \mathrm{l})$. This solution was denatured at $95^{\circ} \mathrm{C}$, placed on ice, and then $50 \mu \mathrm{l}$ was applied to each slide, which were then covered with parafilm and left in a moist chamber at $37^{\circ} \mathrm{C}$ for $12-16 \mathrm{~h}$. The slides were washed twice in formamide ( $50 \%$ in $2 \mathrm{x}$ SSC) and twice in 2x SSC with gentle shaking, and transferred to BN buffer $(100 \mathrm{mM}$ $\mathrm{NaHCO}_{3}, 0.1 \%$ Nonidet P-40) for $10 \mathrm{~min}$ at room temperature. After this, blocking buffer $\left(100 \mathrm{mM} \mathrm{NaHCO}_{3}, 0.05 \%\right.$ Nonidet P- $40,0.02 \% \mathrm{NaN}_{3}, 5 \%$ non-fat dry milk) was applied, and the slides were covered with parafilm and incubated for $10 \mathrm{~min}$ at room temperature. The buffer was removed, streptavidin-Alexa fluor 568 conjugate (Thermo Fisher Scientific, Waltham, MA, USA), diluted 1/50 in blocking buffer, was added, and the slides were covered with parafilm and incubated at $37^{\circ} \mathrm{C}$ for $1 \mathrm{~h}$. The slides were washed with three changes of $\mathrm{BN}$ buffer in a light-tight chamber with gentle shaking. Signal enhancement was done following Pinkel et al. (1986). Fifty microliters of biotinylated goat anti-Avidin D (Vector Laboratories, Burlingame, CA, USA), diluted $1 / 50$ in the blocking buffer, was applied to each slide, which were then covered with parafilm and incubated at $37^{\circ} \mathrm{C}$ for 1 hour. The slides were then washed with $\mathrm{BN}$ buffer, more streptavidin-labeled fluor was added, the slides were washed again with $\mathrm{BN}$ buffer, and then air-dried in the dark at room temperature. Anti-fade medium (ProLong Gold Antifade Reagent with DAPI, Cell Signaling Technology, Danvers, MA, USA) was added and a glass coverslip was placed over the chromosomal preparation. The chromosomes were imaged using a Zeiss 510 NLO Multiphoton microscope and a Zeiss Elyra PS 1 microscope (Carl Zeiss, Pleasanton, CA, USA) with confocal microscopy at the Bio-Imaging Center, Delaware Biotechnology Institute, Newark, DE, USA.

\section{Data analysis}

Genome sizes and total lengths of chromosome sets were compared among species and between sexes in generalized linear models with species and sex as fixed main-effects 
and Poisson error distributions using the glm function in $\mathrm{R}$ ( $\mathrm{R}$ Core Team 2014). The set of relative lengths among species in a multivariate analysis of variance was compared with the Pillai-Bartlett statistic and the manova function in R. Centromeric indexes among species in generalized linear models were compared for each chromosome with species as a fixed effect and Poisson error distributions using the glm function in $\mathrm{R}$. Because chromosomal formulae were different for the $A$. varipes complex versus the $A$. mali and $A$. daucicola complexes, we analyzed the effects of species on relative lengths and centromeric indexes separately within these groups. For genome size, the experimental unit was either 15 heads of female parasitoids and one D. melanogaster head pooled or 15 heads of male parasitoids and 15 heads of female parasitoids pooled. For total lengths of chromosome sets and relative lengths and centromeric indexes of chromosomes, the experimental unit was an individual mitotic cell. Post-hoc comparisons of means were done using the glht and cld functions in the multcomp package in $\mathrm{R}$. We tested the relationships between genome sizes from flow cytometry and total lengths of chromosome sets with linear regression using the $\mathrm{Im}$ function in $\mathrm{R}$. Data are archived on the Ag Data Commons website (data.nal.usda.gov; DOI 10.15482/ USDA.ADC/1329930).

\section{Results}

\section{Genome sizes from flow cytometry}

Haploid genome sizes of Aphelinus differed among species (model deviance $=444.0$; residual deviance $=5.4 ; \mathrm{df}=6,60 ; P<0.0001$ ). Female genome sizes ranged from 330 to $483 \mathrm{Mb}$ so the largest was 1.5 times the smallest (Table 2, which also shows results of multiple comparisons among means of each species). Female and male Aphelinus had similar haploid genome sizes, with female and male sizes within 2-13 Mb (1-4 percent) of one another, so the sexes did not differ significantly (model deviance $=1.1$; residual deviance $=4.3 ; \mathrm{df}=1,59 ; P=0.30$ ). Genomes (averaged across sexes) in the A. mali complex were significantly larger (37-148 Mb or 9-44 percent) than those $A$. varipes complex, and genomes in the $A$. varipes complex were significantly larger (1-59 $\mathrm{Mb}$ or $1-18$ percent) than those in the $A$. daucicola complex (model deviance $=378.10$; residual deviance $=73.3 ; \mathrm{df}=6,60 ; P<0.0001)$. The genome of $A$. rhamni was significantly larger (43-53 Mb or 10-12 percent) than the genomes of the other species in the $A$. mali complex. The genome of $A$. hordei was significantly larger (40-58 $\mathrm{Mb}$ or $9-17$ percent) than the genomes of the other species in the $A$. varipes complex.

\section{Karyotypes}

Species in the $A$. varipes complex had four chromosomes in haploid males and thus eight chromosomes in diploid females, whereas species in the $A$. mali and $A$. daucicola 
Table 2. Haploid genome sizes of nine Aphelinus species estimated from flow cytometry. Shared letters after means indicates that they do not differ significantly.

\begin{tabular}{|c|c|c|c|c|c|c|}
\hline \multirow[b]{2}{*}{ Species complex } & \multirow[b]{2}{*}{ Species } & \multirow[b]{2}{*}{ Sex } & \multirow{2}{*}{ 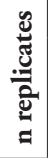 } & \multicolumn{2}{|c|}{ Genome size } & \multirow{2}{*}{$\begin{array}{r}95 \% \mathrm{CI} \\
(\mathrm{Mb})\end{array}$} \\
\hline & & & & (pg) & $(\mathrm{Mb})$ & \\
\hline \multirow{10}{*}{ A. varipes } & \multirow{2}{*}{ A. atriplicis } & female & 6 & 0.361 & $353 a$ & $338-368$ \\
\hline & & male & 3 & 0.366 & $358 \mathrm{a}$ & $337-380$ \\
\hline & \multirow{2}{*}{ A. varipes } & female & 3 & 0.340 & $333 a$ & $313-354$ \\
\hline & & male & 3 & 0.348 & $340 \mathrm{a}$ & $320-362$ \\
\hline & \multirow{2}{*}{ A. certus } & female & 6 & 0.369 & $361 \mathrm{a}$ & $347-377$ \\
\hline & & male & 3 & 0.375 & $367 a$ & $346-390$ \\
\hline & \multirow{2}{*}{ A. kurdjumovi } & female & 4 & 0.356 & $348 \mathrm{a}$ & $331-367$ \\
\hline & & male & 3 & 0.363 & $355 a$ & $334-377$ \\
\hline & \multirow{2}{*}{ A. hordei } & female & 4 & 0.402 & $393 b$ & $374-412$ \\
\hline & & male & 3 & 0.406 & $397 \mathrm{~b}$ & $375-421$ \\
\hline \multirow{2}{*}{ A. daucicola } & \multirow{2}{*}{ A. daucicola } & female & 4 & 0.337 & $330 \mathrm{a}$ & $313-348$ \\
\hline & & male & 3 & 0.351 & $343 a$ & $322-364$ \\
\hline \multirow{6}{*}{ A. mali } & \multirow{2}{*}{ A. glycinis } & female & 6 & 0.442 & $432 c$ & $416-449$ \\
\hline & & male & 5 & 0.441 & $431 \mathrm{c}$ & $413-450$ \\
\hline & \multirow{2}{*}{ A. coreae } & female & 3 & 0.449 & $439 c$ & $416-464$ \\
\hline & & male & 3 & 0.454 & $444 c$ & $421-468$ \\
\hline & \multirow{2}{*}{ A. rhamni } & female & 6 & 0.494 & $483 \mathrm{~d}$ & $466-501$ \\
\hline & & male & 3 & 0.498 & $487 \mathrm{~d}$ & $463-513$ \\
\hline
\end{tabular}

complexes had five chromosomes in haploids and thus ten chromosomes in diploids (Table 3; Figs 1-2). Karyotypes of the $A$. varipes complex usually included a large metacentric chromosome 1 and a small metacentric chromosome 2 and small acrocentric chromosomes 3 and 4, except for A. kurdjumovi, in which the small metacentric chromosome 2 appears to have been replaced by an acrocentric chromosome 2 of similar size; whereas species in the $A$. mali and $A$. daucicola complexes had metacentric chromosomes only, and their chromosomes showed a continuous gradation in length (Tables 4 and 5). Relative lengths of chromosome sets differed significantly among species in the $A$. varipes complex $(F=3.2 ; \mathrm{df}=16,540 ; P<0.0001)$, but did not quite differ significantly among species in the $A$. mali and $A$. daucicola complexes $(F=1.7$; $\mathrm{df}=12,255 ; P=0.07)$.

Centromeric indexes for chromosome 1 did not differ among species, and centromeric indexes for chromosome 2 did not differ among species in the $A$. mali and $A$. daucicola complexes. However, in the $A$. varipes complex, the centromeric index of chromosome 2 in $A$. hordei was significantly lower than in other members of the A. varipes complex. Centromeric indexes for chromosomes 3 and 4 in A. daucicola were significantly lower than those for $A$. rhamni, and the centromeric index for chromosome 5 in $A$. daucicola was significantly lower than those for $A$. coreae and A. rhamni (Table 6). Total lengths of chromosome sets differed among species 
Table 3. Karyotypic features of nine Aphelinus species. Shared letters after means indicate that they do not differ significantly within each sex.

\begin{tabular}{|c|c|c|c|c|c|c|c|}
\hline & \multirow{2}{*}{$\begin{array}{l}\text { species } \\
\text { complex }\end{array}$} & \multirow[b]{2}{*}{ species } & \multirow{2}{*}{ 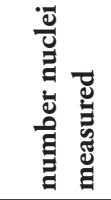 } & \multirow{2}{*}{ 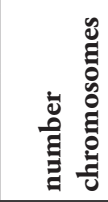 } & \multirow{2}{*}{ 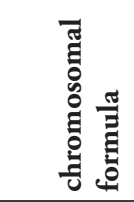 } & \multicolumn{2}{|c|}{\begin{tabular}{|l}
$\begin{array}{l}\text { total length of } \\
\text { chromosome set }(\mu \mathrm{m})\end{array}$ \\
\end{tabular}} \\
\hline & & & & & & mean & $\begin{array}{l}95 \% \text { confidence } \\
\text { interval }\end{array}$ \\
\hline \multirow{9}{*}{ 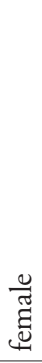 } & \multirow{5}{*}{ A. varipes } & A. atriplicis & 14 & 8 & $4 \mathrm{M}+4 \mathrm{~A}$ & $15.6 \mathrm{ac}$ & $13.7-17.9$ \\
\hline & & A. varipes & 16 & 8 & $4 M+4 A$ & $15.1 \mathrm{ab}$ & $13.3-17.1$ \\
\hline & & A. certus & 19 & 8 & $4 M+4 A$ & $14.0 \mathrm{a}$ & $12.4-15.8$ \\
\hline & & A. kurdjumovi & 13 & 8 & $2 M+6 A$ & $16.8 \mathrm{ac}$ & $14.8-19.2$ \\
\hline & & A. hordei & 8 & 8 & $4 M+4 A$ & $14.3 \mathrm{ab}$ & $11.9-17.1$ \\
\hline & A. daucicola & A. daucicola & 15 & 10 & $10 \mathrm{M}$ & $16.8 \mathrm{ac}$ & $14.8-19.0$ \\
\hline & \multirow{3}{*}{ A. mali } & A. glycinis & 5 & 10 & $10 \mathrm{M}$ & 19.6ac & $16.1-23.9$ \\
\hline & & A. coreae & 6 & 10 & $10 \mathrm{M}$ & $21.3 c$ & $17.9-25.4$ \\
\hline & & A. rhamni & 19 & 10 & $10 \mathrm{M}$ & $18.4 \mathrm{bc}$ & $16.5-20.4$ \\
\hline \multirow{6}{*}{$\frac{\ddot{\Xi}}{\overparen{\Xi}}$} & \multirow{3}{*}{ A. varipes } & A. atriplicis & 3 & 4 & $2 M+2 A$ & $16.3 \mathrm{ab}$ & $12.3-21.6$ \\
\hline & & A. certus & 3 & 4 & $2 \mathrm{M}+2 \mathrm{~A}$ & $25.0 \mathrm{bc}$ & $19.9-31.3$ \\
\hline & & A. hordei & 21 & 4 & $2 \mathrm{M}+2 \mathrm{~A}$ & $17.8 \mathrm{~b}$ & $16.1-19.7$ \\
\hline & A. daucicola & A. daucicola & 7 & 5 & $5 \mathrm{M}$ & $23.7 \mathrm{ac}$ & $20.4-27.6$ \\
\hline & \multirow{2}{*}{ A. mali } & A. coreae & 6 & 5 & $5 \mathrm{M}$ & $29.8 \mathrm{c}$ & $25.8-34.5$ \\
\hline & & A. rhamni & 4 & 5 & $5 \mathrm{M}$ & $22.5 \mathrm{bc}$ & $18.3-27.7$ \\
\hline
\end{tabular}

$\mathrm{M}=$ metacentric $; \mathrm{A}=$ acrocentric.

Table 4. Relative lengths of chromosomes in Aphelinus species. Means with $95 \%$ confidence intervals in parentheses.

\begin{tabular}{|c|c|c|c|c|c|c|}
\hline \multirow{3}{*}{ Species complex } & \multirow{3}{*}{ Species } & \multicolumn{5}{|c|}{ Chromosome } \\
\hline & & 1 & 2 & 3 & 4 & 5 \\
\hline & & \multicolumn{5}{|c|}{ Relative length } \\
\hline \multirow{10}{*}{ A. varipes } & \multirow{2}{*}{ A. atriplicis } & 40 & 26 & 18 & 16 & \\
\hline & & $(38-42)$ & $(24-28)$ & $(17-20)$ & $(14-17)$ & \\
\hline & \multirow{2}{*}{ A. varipes } & 41 & 26 & 18 & 15 & \\
\hline & & $(39-43)$ & $(24-27)$ & $(17-19)$ & $(14-17)$ & \\
\hline & \multirow{2}{*}{ A. certus } & 40 & 26 & 18 & 16 & \\
\hline & & $(38-43)$ & $(24-28)$ & $(17-20)$ & $(14-17)$ & \\
\hline & \multirow{2}{*}{ A. kurdjumovi } & 43 & 24 & 18 & 15 & \\
\hline & & $(40-45)$ & $(22-26)$ & $(17-20)$ & $(14-17)$ & \\
\hline & \multirow{2}{*}{ A. hordei } & 41 & 25 & 19 & 16 & \\
\hline & & $(37-44)$ & $(23-27)$ & $(17-21)$ & $(14-18)$ & \\
\hline \multirow{2}{*}{ A. daucicola } & \multirow{2}{*}{ A. daucicola } & 24 & 22 & 19 & 18 & 18 \\
\hline & & $(23-26)$ & $(20-24)$ & $(18-21)$ & $(17-20)$ & $(17-20)$ \\
\hline \multirow{6}{*}{ A. mali } & \multirow{2}{*}{ A. glycinis } & 24 & 22 & 21 & 18 & 18 \\
\hline & & $(21-27)$ & $(19-25)$ & $(18-24)$ & $(16-21)$ & $(16-21)$ \\
\hline & \multirow{2}{*}{ A. coreae } & 24 & 22 & 20 & 18 & 18 \\
\hline & & $(21-27)$ & $(20-25)$ & $(18-23)$ & $(16-21)$ & $(16-21)$ \\
\hline & \multirow{2}{*}{ A. rhamni } & 24 & 22 & 20 & 18 & 18 \\
\hline & & $(23-26)$ & $(21-24)$ & $(19-22)$ & $(17-19)$ & $(17-19)$ \\
\hline
\end{tabular}




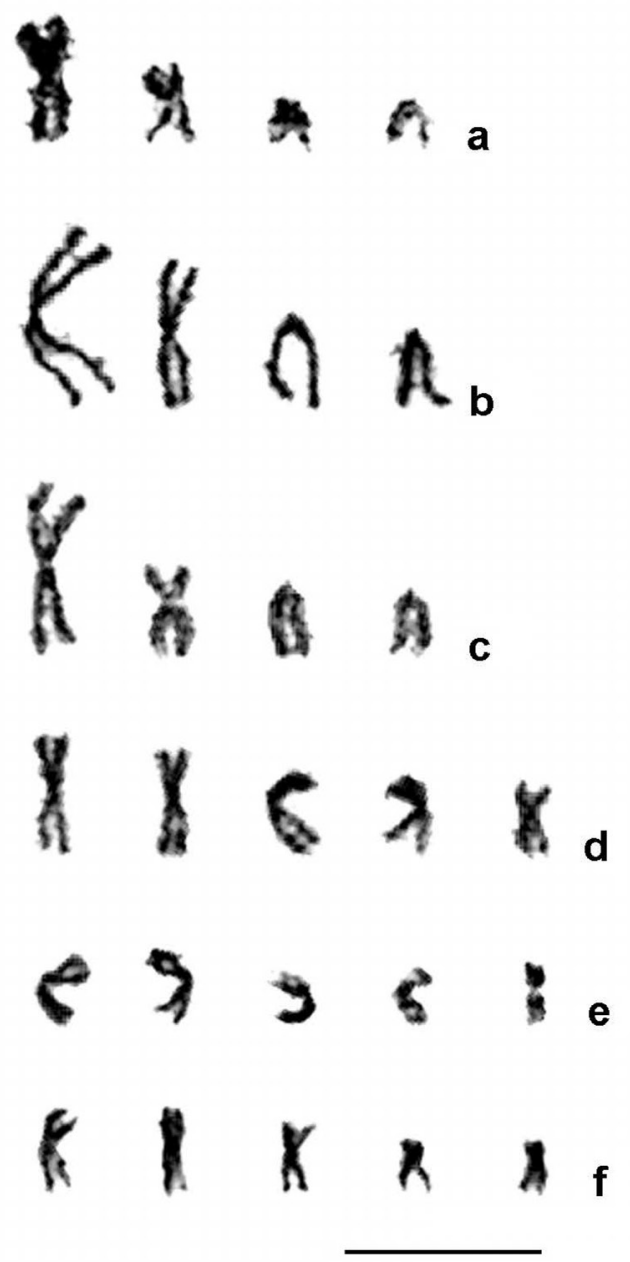

Figure I. Haploid mitotic karyograms of six Aphelinus species. a A. atriplicis $\mathbf{b}$ A. certus $\mathbf{c} A$. hordei $\mathbf{d} A$. coreae e $A$. rhamni $\mathbf{f}$. daucicola. Species in the $A$. varipes complex have $\mathrm{n}=4$ versus $\mathrm{n}=5$ in the $A$. mali and $A$. daucicola complexes. Scale bar: $10 \mu \mathrm{m}$.

(model deviance $=65.1 ;$ residual deviance $=153.2 ; \mathrm{df}=8,150 ; P<0.0001)$ and between sexes (model deviance $=34.3$; residual deviance $=118.9 ; \mathrm{df}=1,149 ; P<$ 0.0001 ). Total lengths ranged from 14 to $21 \mu \mathrm{m}$ so the longest set was 1.5 times the shortest (Table 3). Total lengths were significantly greater in the $A$. mali complex than in the $A$. varipes complex for both males and females, with the values in $A$. daucicola complex intermediate between these extremes (females: model deviance $=20.5$; residual deviance $=92.8 ; \mathrm{df}=2,112 ;<0.0001 ;$ males: model deviance $=$ 26.2; residual deviance $=38.8 ; \mathrm{df}=2,41 ; P<0.0001)$. Mean total chromosome length correlated with mean genome size estimated from flow cytometry $(F=6.3$; 


\section{(C) " " a

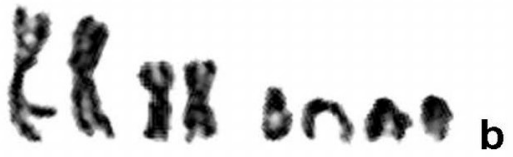 \\ HX as ...}

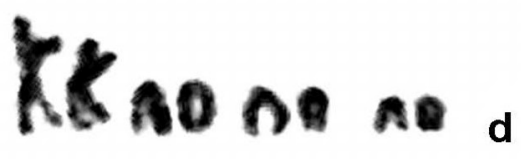

Xlis at a a

\section{II \& \& $\|$ o}

$8 x \times x \times 8 \times x \times 2$

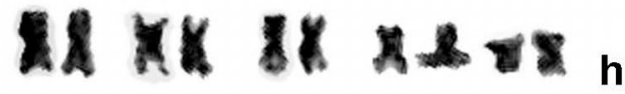

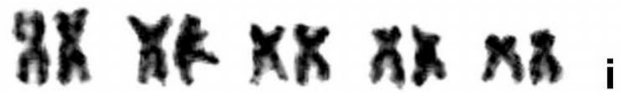

Figure 2. Diploid mitotic karyograms of nine Aphelinus species. a A. atriplicis $\mathbf{b}$ A. certus $\mathbf{c}$ A. hordei $\mathbf{d} A$. kurdjumovi e $A$. varipes $\mathbf{f} A$. coreae $\mathbf{g} A$. glycinis $\mathbf{h} A$. rhamni, $\mathbf{i} A$. daucicola. Species in the $A$. varipes complex have $2 \mathrm{n}=8$ versus $2 \mathrm{n}=10$ in the $A$. mali and $A$. daucicola complexes. Scale bar: $10 \mu \mathrm{m}$.

$\mathrm{df}=1,7 ; P=0.04 ; r^{2}=0.47$; Fig. 3 ), primarily because of the difference in total chromosome length between the $A$. mali and $A$. varipes complexes.

Hybridization with a $28 \mathrm{~S}$ rDNA probe revealed a single rDNA cluster on chromosomes of the haploid set and two rDNA clusters in the diploid set (Fig. 4). These clusters were near the centromere on a medium-sized metacentric chromosome. 
Table 5. Centromeric indexes of chromosomes in Aphelinus species. Means ( $95 \%$ confidence intervals); shared letters within a species complex and chromosome indicate means that are not significantly different.

\begin{tabular}{|c|c|c|c|c|c|c|}
\hline \multirow{3}{*}{ complex } & \multirow{3}{*}{ species } & \multicolumn{5}{|c|}{ Chromosome } \\
\hline & & 1 & 2 & 3 & 4 & 5 \\
\hline & & \multicolumn{5}{|c|}{ Centromeric index } \\
\hline \multirow{10}{*}{ A. varipes } & \multirow{2}{*}{ A. atriplicis } & $46 a$ & $47 \mathrm{~b}$ & 0 & 0 & \\
\hline & & $(44-49)$ & $(45-50)$ & & & \\
\hline & \multirow{2}{*}{ A. varipes } & $46 a$ & $47 \mathrm{~b}$ & 0 & 0 & \\
\hline & & $(44-49)$ & $(45-49)$ & & & \\
\hline & \multirow{2}{*}{ A. certus } & $46 a$ & $46 a b$ & 0 & 0 & \\
\hline & & $(44-49)$ & $(44-48)$ & & & \\
\hline & \multirow{2}{*}{ A. kurdjumovi } & $47 a$ & 0 & 0 & 0 & \\
\hline & & $(44-49)$ & & & & \\
\hline & \multirow{2}{*}{ A. hordei } & $47 a$ & $41 \mathrm{a}$ & 0 & 0 & \\
\hline & & $(44-51)$ & $(38-45)$ & & & \\
\hline \multirow{8}{*}{ A. mali and A. daucicola } & \multirow{2}{*}{ A. daucicola } & $45 a$ & $45 a$ & $41 \mathrm{a}$ & $39 a$ & $38 \mathrm{a}$ \\
\hline & & $(43-48)$ & $(43-48)$ & $(38-43)$ & $(37-41)$ & $(36-40)$ \\
\hline & \multirow{2}{*}{ A. glycinis } & $48 a$ & $44 a$ & $44 \mathrm{ab}$ & $44 \mathrm{ab}$ & $42 \mathrm{ab}$ \\
\hline & & $(43-52)$ & $(40-48)$ & $(40-48)$ & $(40-49)$ & $(39-47)$ \\
\hline & \multirow{2}{*}{ A. coreae } & $44 a$ & $47 a$ & $43 \mathrm{ab}$ & $44 a b$ & $44 \mathrm{~b}$ \\
\hline & & $(41-48)$ & $(43-51)$ & $(40-47)$ & $(40-47)$ & $(40-47)$ \\
\hline & \multirow{2}{*}{ A. rhamni } & $46 a$ & $46 a$ & $45 b$ & $45 b$ & $43 \mathrm{~b}$ \\
\hline & & $(44-49)$ & $(44-48)$ & $(43-47)$ & $(43-47)$ & $(41-45)$ \\
\hline
\end{tabular}

Table 6. Analysis of deviance for differences in centromeric indexes among species of Aphelinus; acrocentric chromosomes were not included in these analyses.

\begin{tabular}{l|l|c|c|c|c|c}
\hline \multirow{2}{*}{ complex } & \multirow{2}{*}{ chromosome } & \multicolumn{2}{|c|}{ model } & \multicolumn{3}{c}{ residual } \\
\cline { 3 - 7 } & & df & deviance & df & deviance & P \\
\hline \multirow{2}{*}{ A varipes } & 1 & 4 & 0.2 & 135 & 23.1 & 1.00 \\
\cline { 2 - 7 } & 2 & 3 & 9.3 & 110 & 22.3 & 0.03 \\
\hline \multirow{4}{*}{ A. mali and A. daucicola } & 1 & 3 & 1.8 & 86 & 20.7 & 0.62 \\
\cline { 2 - 7 } & 2 & 3 & 1.2 & 86 & 23.0 & 0.74 \\
\cline { 2 - 7 } & 3 & 3 & 7.2 & 86 & 33.2 & 0.07 \\
\cline { 2 - 7 } & 4 & 3 & 16.6 & 86 & 29.0 & 0.0008 \\
\hline
\end{tabular}

\section{Discussion}

The large genome size differences between the $A$. varipes complex versus the $A$. mali complex matched the phylogenetic divergence between these complexes (Heraty et al. 2007). The difference between the complexes is also supported by the difference in karyotypes: four chromosomes with one-two metacentrics and two-three acrocentrics in the $A$. varipes complex versus five metacentric chromosomes in the $A$. mali complex. 


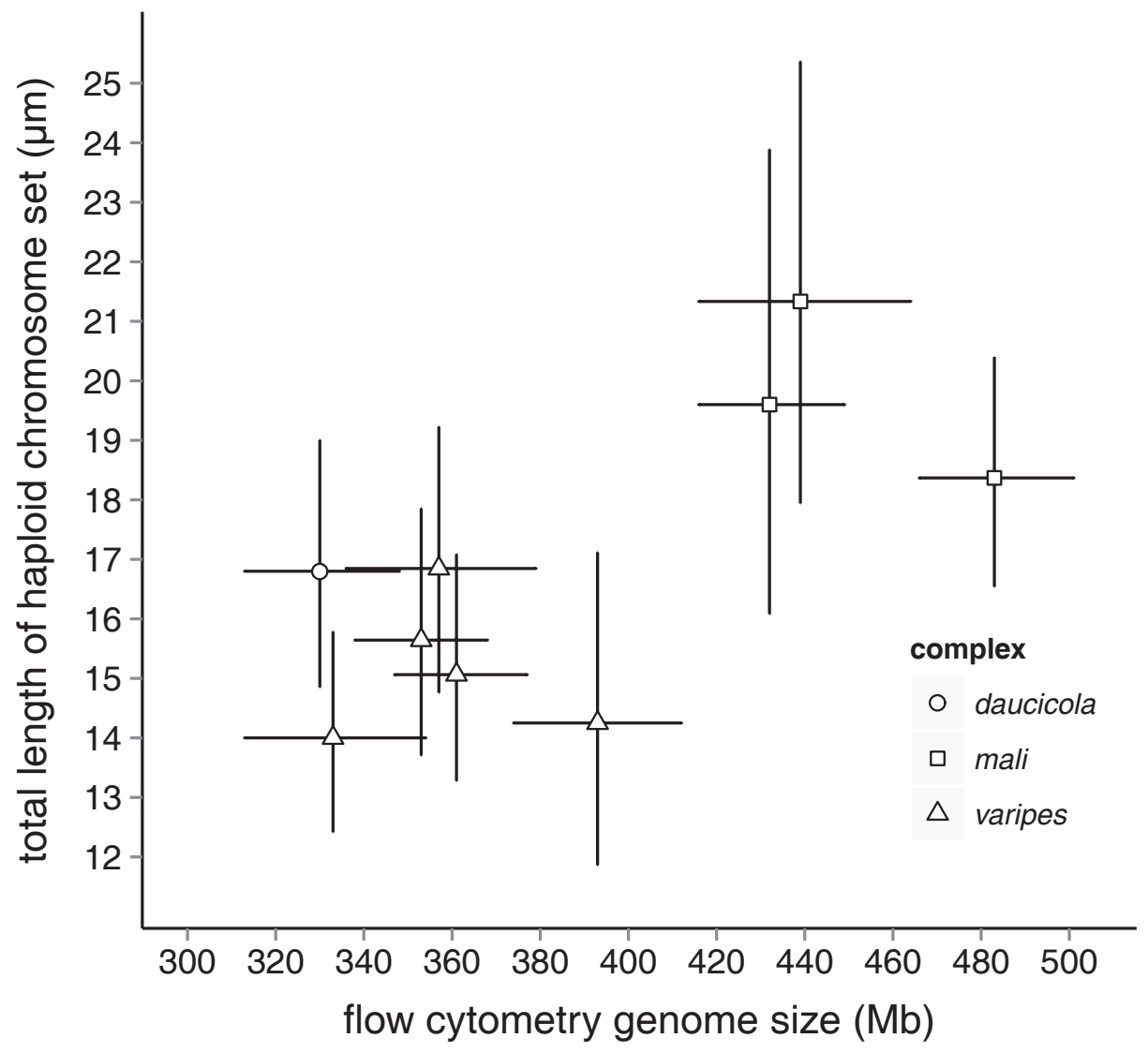

Figure 3. Total length of chromosome set $(\mu \mathrm{m})$ versus flow cytometry genome size $(\mathrm{Mb})$ for nine Aphelinus species. Error bars are 95\% confidence intervals.

However, the additional chromosome in the $A$. mali complex does not necessarily account for a corresponding increase in genome size, because $A$. daucicola also has five chromosomes and yet has the smallest genome we observed. Four haploid genome sizes have been published for the family Aphelinidae, including an estimate of 635 $\mathrm{Mb}(=0.65 \mathrm{pg})$ for Aphelinus abdominalis (Dalman, 1820) (Ardila-Garcia et al. 2010) which is much larger than our estimates for other species of Aphelinus. However, beyond Aphelinus, other Hymenoptera genera have genome sizes spanning wide ranges (e.g., some ants, Tapinoma Förster, 1850, 362-597 Mb; Solenopsis Westwood, 1840, 372-753 Mb; http://www.genomesize.com). This also applies to some genera of parasitoids, e.g. Leptopilina Förster, 1869 (Figitidae) with genome sizes ranging from 363 to $520 \mathrm{Mb}$ (Gokhman et al. 2011).

Genome size has been hypothesized to depend on several factors, including eusociality, parasitism, and developmental biology in insects (Ardila-Garcia and Gregory 2009, Gregory 2002, Johnston et al. 2004). These hypotheses come from the asso- 

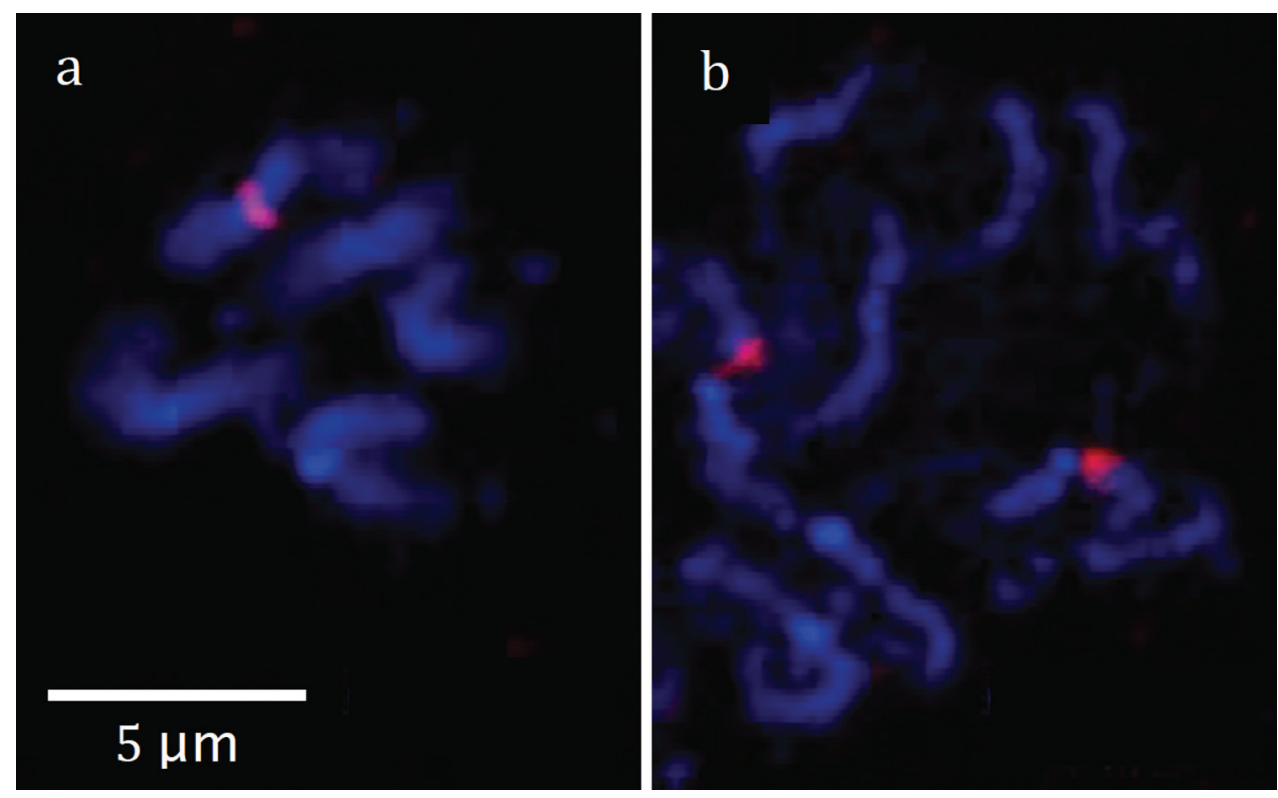

Figure 4. Fluorescence in situ hybridization with $28 \mathrm{~S}$ rDNA probe. a metaphase chromosomes of the haploid karyotype and $\mathbf{b}$ prometaphase chromosomes of the diploid karyotype of $A$. coreae. Red = hybridization signal (a single rDNA cluster in the haploid set and paired clusters in the diploid set), blue = counterstaining of chromosomes with DAPI.

ciations between genome size, cell size, and cell division rates found in many taxa (Ardila-Garcia and Gregory 2009, Gregory 2005). The mean genome size for species of parasitic Hymenoptera (293 Mb) does not differ greatly from the mean genome size for species of eusocial Hymenoptera (333 Mb), but the genomes for both groups are significantly smaller than those for species of non-parasitoid solitary Hymenoptera (469 Mb) (Ardila-Garcia and Gregory 2009). However, it is unclear why there should be so much variation in genome size among species of Leptopilina or Aphelinus, given the very similar biologies within each genus.

Mapping karyotypic data on a molecular phylogeny of Aphelinus and two outgroup species allowed reconstruction of karyotype evolution in the species we studied (Fig. 5). The phylogeny was modified from Heraty et al. (2007) with results from Heraty et al. (2013), Kim and Heraty (2012), and unpublished data. Chromosomal formulae were mapped on the phylogeny using Mesquite (Maddison and Maddison 2016). Chromosomal formulae for Aphytis mytilaspidis (Le Baron, 1870) and Encarsia formosa Gahan, 1924 are from (Gokhman 2003). Concerning chromosome number, Aphelinus asychis Walker, 1839, has four chromosomes (Gokhman 2003), which is what we found for all the species we studied in the $A$. varipes complex. On the other hand, we found five chromosomes for $A$. daucicola and three species in the $A$. mali complex, which is also the chromosome number reported for Aphelinus mali (Haldeman, 1851) (Viggiani 1967). 


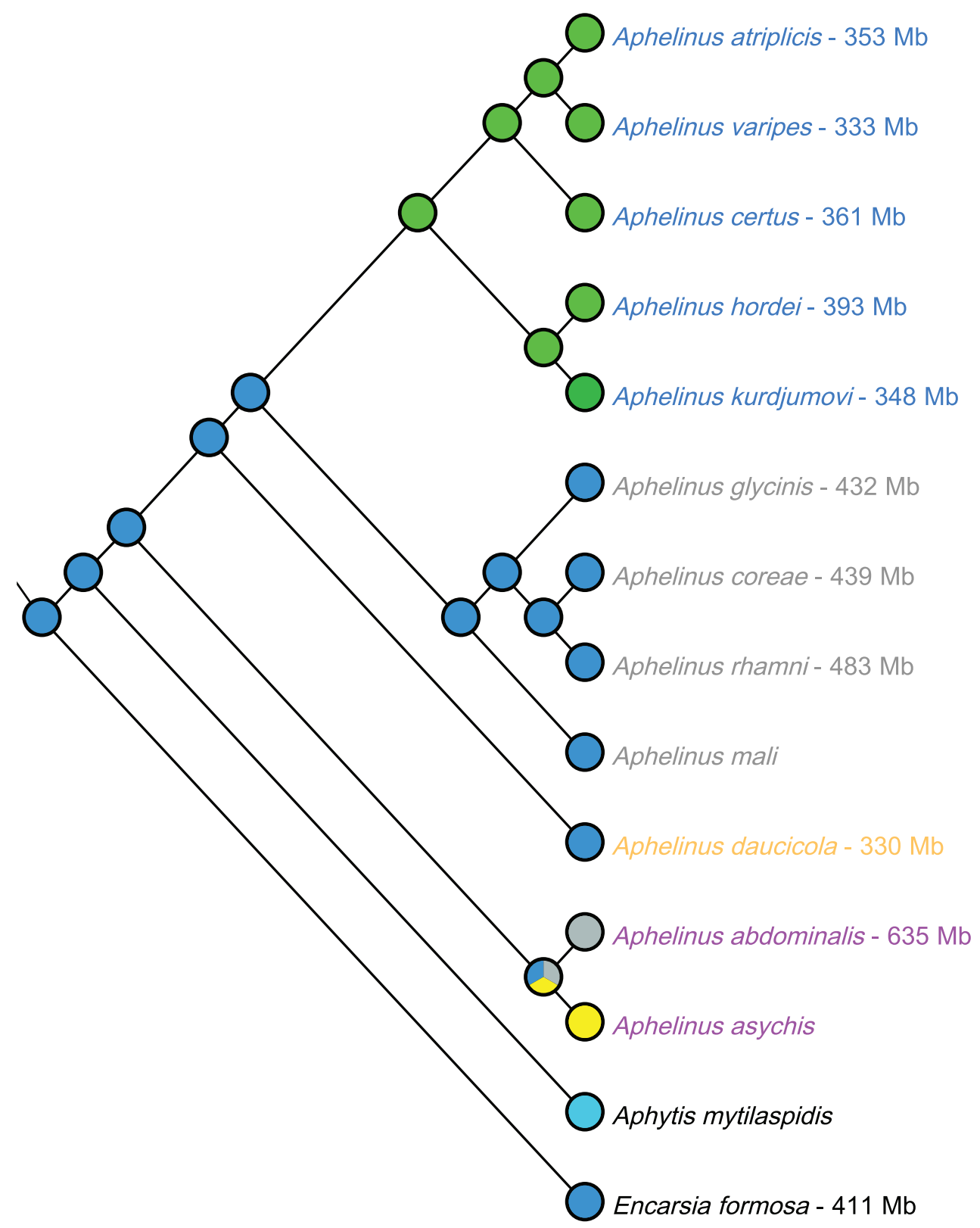

Figure 5. Chromosomal formulae and genome sizes on phylogeny of Aphelinus species and several outgroups. Blue $=5$ metacentric chromosomes; aqua $=1$ metacentric and 4 acrocentric chromosomes; green $=2$ metacentric and 2 acrocentric chromosomes; dark green $=1$ metacentric and 3 acrocentric chromosomes; yellow = 2 metacentric, 1 subtelocentric, and 1 acrocentric chromosome; grey = unknown. Numbers after species names are genome sizes estimated from flow cytometry; values for Aphelinus abdominalis and E. formosa are from (Ardila-Garcia et al. 2010). The different colors for species of Aphelinus indicate membership in the four species complexes for which data are available. 
The $A$. varipes and $A$. mali complexes are sister clades, but $A$. asychis is the most basal species in the phylogeny of the genus, at least for the species for which there are phylogenetic data. This information alone would suggest four chromosomes is the ancestral state. However, five or six chromosomes are the numbers most frequently reported in chalcidoids (although it has been hypothesized that 9-10 is the ancestral state) (Gokhman 2009). Furthermore, five chromosomes has been reported for Aphytis mytilaspidis (Rössler and DeBach 1973), a species in the genus most closely related to Aphelinus for which chromosome number has been reported, and five chromosomes have been reported for many species of Encarsia Förster, 1878, a genus of aphelinids in another subfamily of Aphelinidae (Gokhman 2009). Chromosomal fusion (and hence decreased chromosome number) is a trend of karyotype evolution in many groups of organisms, including parasitic Hymenoptera (Gokhman 2009). Chromosomal fissions are also possible, but they are substantially less frequent, probably because they break existing linkage groups and therefore can decrease fitness. Thus, the reduced chromosome number in $A$. asychis has probably arisen independently of that in the $A$. varipes complex, because these two groups also have different karyotype structures. Aphelinus asychis has a haploid karyotype with two metacentric chromosomes, a subtelocentric chromosome and an acrocentric chromosome, with the three smallest chromosomes being similar in size (Gokhman 2009). The same chromosome number in $A$. asychis and in the A. varipes complex could be an example of karyotypic orthoselection (White 1973), i.e. similar karyotypes with independent origins. However, the hypothesis of chromosomal fusion giving rise to four chromosomes in the $A$. varipes complex cannot explain the significant and substantially smaller genome sizes in this complex compared to those in the $A$. mali complex.

Chromosomes in the $A$. varipes complex differ from those in the $A$. mali complex in relative length and centromeric indices. The longest metacentric chromosome in species in the $A$. varipes complex is much longer than the other chromosomes. We suggest that this metacentric chromosome resulted from a fusion of two smaller chromosomes from an ancestral karyotype with five chromosomes. Species in the $A$. varipes complex have two smaller acrocentrics that, in turn, could originate from metacentric chromosomes of the ancestral karyotype via pericentric inversions. Moreover, the position of the centromere of the second largest chromosome underwent further changes in two sister species in the $A$. varipes complex, $A$. kurdjumovi and $A$. hordei. The centromere is significantly shifted in $A$. hordei $(\mathrm{CI}=41$ versus 46 in A. certus, and 47 in A. atriplicis and $A$. varipes), and is further moved to a terminal position in $A$. kurdjumovi $(\mathrm{CI}=0)$. We propose that consecutive pericentric inversions in $A$. hordei and A. kurdjumovi would be the most parsimonious explanation. These chromosomal rearrangements in the $A$. varipes complex are an example of a general trend in karyotype evolution in parasitic Hymenoptera, namely, karyotypic dissymmetrization, which involves an increase in size differentiation between chromosomes and an increase in the proportion of acrocentric chromosomes (Gokhman 2009).

A recent review of the distribution of rDNA sites on chromosomes of parasitic $\mathrm{Hy}$ menoptera showed that the number of these sites correlates with chromosome number (Gokhman et al. 2014). We found that this is also true for at least one Aphelinus species: haploid males of $A$. coreae, with their low number of chromosomes $(n=5)$, had a single 
rDNA site, while diploid females of $A$. coreae had two rDNA sites. Fluorescence in situ hybridization is especially useful for studying karyotypes with morphologically similar chromosomes that are difficult to recognize with conventional staining, like the chromosomes of $A$. coreae and other species in the $A$. mali and $A$. daucicola complexes.

Total chromosomal length was correlated with genome size in Aphelinus, but this was because of the difference in chromosome length between the $A$. mali and $A$. varipes complexes. Although a similar correlation was found for species in the family Figitidae (Gokhman et al. 2014), only large differences in chromosome length were distinguished in both cases, probably because of intraspecific variation in chromosomal condensation. Total lengths of male chromosomes exceeded those of females, although male and female genome sizes did not differ, and indeed it would be surprising if they did, given that males inherit their chromosomes from their mothers. The difference in the chromosome length between males and females may have resulted from differences in chromosomal condensation between the sexes, and this could compensate for the differences in chromatin available for transcription in the haploid and diploid genomes.

\section{Conclusions}

Differences as large as 44\% were found in genome size between Aphelinus species, which is surprising given the similarity in their morphology and life history. Mean total chromosome length correlated with mean genome size. The differences in genome size and total chromosome length between species complexes matched the phylogenetic divergence between species complexes. Chromosomal rearrangements in the $A$. varipes complex are an example of karyotypic dissymmetrization, which involves an increase in size differentiation between chromosomes and an increase in the proportion of acrocentric chromosomes, which is a general trend in karyotype evolution in parasitic Hymenoptera.

\section{Acknowledgements}

We thank Kathryn Lanier and Joshua Rhoades, USDA-ARS, Newark, Delaware, for rearing the Aphelinus cultures. We thank Deni Galileo in the CTCR Core Facility, University of Delaware, for assistance with the flow cytometer analyses and Jeffrey Caplan and Jean Ross in the Bio-Imaging Center, Delaware Biotechnology Institute, for providing facilities and assistance with imaging of fluorescence in situ hybridizations. These core facilities are supported by the Delaware INBRE program, with a grant from the National Institute of General Medical Sciences grant (P20 GM103446) from the National Institutes of Health and the state of Delaware and by a National Science Foundation EPSCoR grant (IIA-1301765). This research was funded by the United States Department of Agriculture, Agriculture Research Service and by Award DEB 1257601 from the National Science Foundation to JBW and KRH and Award 15-04-07709 from the Russian Foundation for Basic Research to VEG. The funders had no role in study design, data collection and analysis, decision to publish, or preparation of the manuscript. 


\section{References}

Ardila-Garcia AM, Gregory TR (2009) An exploration of genome size diversity in dragonflies and damselflies (Insecta: Odonata). Journal of Zoology 278: 163-173. https://doi. org/10.1111/j.1469-7998.2009.00557.x

Ardila-Garcia AM, Umphrey GJ, Gregory TR (2010) An expansion of the genome size dataset for the insect order Hymenoptera, with a first test of parasitism and eusociality as possible constraints. Insect Molecular Biology 19: 337-346. https://doi.org/10.1111/j.13652583.2010.00992.x

Ashmead WH (1888) Descriptions of some new North American Chalcididae. III: Euderinae (Hymenoptera: Chalcidoidea). Canadian Entomologist 20: 101-107. https://doi. org/10.4039/Ent20101-6

Baur H, Kranz-Baltensperger Y, Cruaud A, Rasplus J-Y, Timokhov AV, Gokhman VE (2014) Morphometric analysis and taxonomic revision of Anisopteromalus Ruschka (Hymenoptera: Chalcidoidea: Pteromalidae) - an integrative approach. Systematic Entomology 39: 691-709. https://doi.org/10.1111/syen.12081

Biemont C (2008) Within-species variation in genome size. Heredity 101: 297-298. https:// doi.org/10.1038/hdy.2008.80

Bosco G, Campbell P, Leiva-Neto JT, Markow TA (2007) Analysis of Drosophila species genome size and satellite DNA content reveals significant differences among strains as well as between species. Genetics 177: 1277-1290. https://doi.org/10.1534/genetics.107.075069

Eggleton P, Belshaw R (1992) Insect parasitoids: an evolutionary overview. Philosophical Transactions of the Royal Society of London Series B: Biological Sciences 337: 1-20. https://doi.org/10.1098/rstb.1992.0079

Evans GA, Schauff ME, Kokyokomi ML, Yokomi RK (1995) A new species of Aphelinus (Hymenoptera, Aphelinidae) that parasitizes the Spirea aphid, Aphis spiraecola Patch (Homoptera, Aphididae). Proceedings of the Entomological Society of Washington 97: 17-21. https://doi.org/10.1201/b17450-8

Förster A (1841) Beiträge zur Monographie der Pteromalinen Nees 1 Heft:45. Aachen, 47 pp. Gadau J, Rütten K, Neusser M (2014) Parasitoid wasps (Hymenoptera). In: Sharakhov IV (Ed.) Protocols for cytogenetic mapping of arthropod genomes. CRC Press, Boca Raton, Florida 257-284.

Gahan AB (1924) Some new parasitic Hymenoptera with notes on several described forms. Proceedings of the United States National Museum 65: 9.

Galbraith DW, Harkins KR, Maddox JM, Ayres NM, Sharma DP, Firoozabady E (1983) Rapid flow cytometric analysis of the cell-cycle in intact plant-tissues. Science 220: 1049-1051. https://doi.org/10.1126/science.220.4601.1049

Girault AA (1913) Australian Hymenoptera Chalcidoidea - IV. Memoirs of the Queensland Museum 2: 181-295.

Godfray HCJ (1994) Parasitoids: Behavioral and Evolutionary Ecology. Princeton University Press, Princeton, New Jersey, 473 pp.

Gokhman VE (2003) Karyotypes of parasitic Hymenoptera: evolution, systematic and phylogenetic implications. PhD dissertation, Moscow, Moscow State University, Russia, 338 pp. 
Gokhman VE (2009) Karyotypes of parasitic Hymenoptera. Springer, 183 pp. https://doi. org/10.1007/978-1-4020-9807-9

Gokhman VE, Anokhin BA, Kuznetsova VG (2014) Distribution of $18 \mathrm{~S}$ rDNA sites and absence of the canonical TTAGG insect telomeric repeat in parasitoid Hymenoptera. Genetica 142: 317-322. https://doi.org/10.1007/s10709-014-9776-3

Gokhman VE, Johnston JS, Small C, Rajwani R, Hanrahan SJ, Govind S (2011) Genomic and karyotypic variation in Drosophila parasitoids (Hymenoptera, Cynipoidea, Figitidae). Comparative Cytogenetics 5: 211-221. https://doi.org/10.3897/compcytogen.v5i3.1435

Gokhman VE, Kuznetsova VG (2006) Comparative insect karyology: current state and applications. Entomological Review 86: 352-368. https://doi.org/10.1134/S0013873806030110

Gregory TR (2002) Genome size and developmental complexity. Genetica 115: 131-146. https://doi.org/10.1023/A:1016032400147

Gregory TR (2005) Synergy between sequence and size in large-scale genomics. Nature Reviews Genetics 6: 699-708. https://doi.org/10.1038/nrg1674

Gregory TR, Johnston JS (2008) Genome size diversity in the family Drosophilidae. Heredity 101: 228-238. https://doi.org/10.1038/hdy.2008.49

Gregory TR, Nathwani P, Bonnett TR, Huber DPW (2013) Sizing up arthropod genomes: an evaluation of the impact of environmental variation on genome size estimates by flow cytometry and the use of qPCR as a method of estimation. Genome 56: 505-510. https:// doi.org/10.1139/gen-2013-0044

Haldeman SS (1851) Eriophilus mali. Pennsylvania Farm Journal 1: 130-131.

Hanrahan SJ, Johnston JS (2011) New genome size estimates of 134 species of arthropods. Chromosome Research 19: 809-823. https://doi.org/10.1007/s10577-011-9231-6

Hare EE, Johnston JS (2011) Genome size determination using flow cytometry of propidium iodide-stained nuclei. Molecular Methods for Evolutionary Genetics 772: 3-12. https:// doi.org/10.1007/978-1-61779-228-1_1

Hayat M (1972) The species of Aphelinus Dalman, 1820 [Hymenoptera: Aphelinidae] from India. Entomophaga 17: 49-58. https://doi.org/10.1007/BF02371072

Hayat M (1994) Taxonomic studies on Aphelinus (Hymenoptera: Aphelinidae). VI. Records of two known and descriptions of two new species from the Oriental Region. Entomon 19: 35-39.

Hayat M (1998) Aphelinidae of India (Hymenoptera: Chalcidoidea): a taxonomic revision. Memoirs on Entomology, International 13, 432 pp.

Hayat M, Fatima K (1992) Taxonomic studies on Aphelinus (Hymenoptera: Aphelinidae). 5. Description of a new species and further records of $A$. gossypii, with a new synonymy. Entomon 17: 103-107.

Heraty JM, Burks RA, Cruaud A, Gibson GAP, Liljeblad J, Munro J, Rasplus JY, Delvare G, Jansta P, Gumovsky A, Huber J, Woolley JB, Krogmann L, Heydon S, Polaszek A, Schmidt S, Darling DC, Gates MW, Mottern J, Murray E, Dal Molin A, Triapitsyn S, Baur H, Pinto JD, van Noort S, George J, Yoder M (2013) A phylogenetic analysis of the megadiverse Chalcidoidea (Hymenoptera). Cladistics 29: 466-542. https://doi. org/10.1111/cla.12006

Heraty JM, Woolley JB, Hopper KR, Hawks DL, Kim JW, Buffington M (2007) Molecular phylogenetics and reproductive incompatibility in a complex of cryptic species of 
aphid parasitoids. Molecular Phylogenetics and Evolution 45: 480-493. https://doi. org/10.1016/j.ympev.2007.06.021

Hopper KR, Woolley JB, Hoelmer K, Wu K, Qiao G-X, Lee S (2012) An identification key to species in the mali complex of Aphelinus (Hymenoptera, Chalcidoidea) with descriptions of three new species. Journal of Hymenoptera Research 26: 73-96. https://doi. org/10.3897/jhr.26.2584

Howard LO (1908) Upon the Aphis feeding species of Aphelinus. Entomological News 19: 365-367.

Imai HT, Taylor RW, Crosland MWJ, Crozier RH (1988) Modes of spontaneous chromosomal mutation and karyotype evolution in ants with reference to the minimum interaction hypothesis. Japanese Journal of Genetics 63: 159-185. https://doi.org/10.1266/jjg.63.159

Jacobson AL, Johnston JS, Rotenberg D, Whitfield AE, Booth W, Vargo EL, Kennedy GG (2013) Genome size and ploidy of Thysanoptera. Insect Molecular Biology 22: 12-17. https://doi.org/10.1111/j.1365-2583.2012.01165.x

Johnston JS, Ross LD, Beani L, Hughes DP, Kathirithamby J (2004) Tiny genomes and endoreduplication in Strepsiptera. Insect Molecular Biology 13: 581-585. https://doi. org/10.1111/j.0962-1075.2004.00514.x

Kim JW, Heraty J (2012) A phylogenetic analysis of the genera of Aphelininae (Hymenoptera: Aphelinidae), with a generic key and descriptions of new taxa. Systematic Entomology 37: 497-549. https://doi.org/10.1111/j.1365-3113.2012.00625.x

Kurdjumov NV (1913) Notes on European species of the genus Aphelinus Dalm. (Hymenoptera, Chalcidoidea), parasitic upon the plant-lice. Russian Review of Entomology 13: 266-270.

Levan A, Fredga K, Sandberg AA (1964) Nomenclature for centromeric position on chromosomes. Hereditas 52: 201-220. https://doi.org/10.1111/j.1601-5223.1964.tb01953.x

Lopes DM, de Carvalho CR, Clarindo WR, Praca MM, Tavares MG (2009) Genome size estimation of three stingless bee species (Hymenoptera, Meliponinae) by flow cytometry. Apidologie 40: 517-523. https://doi.org/10.1051/apido/2009030

Macgregor HC, Varley JM (1988) Working with animal chromosomes. John Wiley \& Sons, Chichester, 290 pp.

Maddison WP, Maddison DR (2016) Mesquite: a modular system for evolutionary analysis. Version 3.11 http://mesquiteproject.org.

Matsumoto K, Yamamoto DS, Sumitani M, Lee JM, Hatakeyama M, Oishi K (2002) Detection of a single copy gene on a mitotic metaphase chromosome by fluorescence in situ hybridization (FISH) in the sawfly, Athalia rosae (Hymenoptera). Archives of Insect Biochemistry and Physiology 49: 34-40. https://doi.org/10.1002/arch.10005

Nikol'skaya MN, Yasnosh VA (1966) Aphelinidae of the European Part of the USSR and Caucasus (Chalcidoidea: Aphelinidae). Nauka, Leningrad, 295 pp.

Pan MX (1992) A new species of Aphelinus Dalman from Zhejiang province, China (Hymenoptera: Aphelinidae). Acta Zootaxonomica Sinica 17: 75-77 [In Chinese].

Pinkel D, Straume T, Gray JW (1986) Cytogenetic analysis using quantitative, high-sensitivity, fluorescence hybridization. Proceedings of the National Academy of Sciences of the United States of America 83: 2934-2938. https://doi.org/10.1073/pnas.83.9.2934 
Prinsloo GL, Neser OC (1994) The southern African species of Aphelinus Dalman (Hymenoptera: Aphelinidae), parasitoids of aphids (Homoptera: Aphidoidea). Journal of African Zoology 108: 143-162.

R_Core_Team (2014) R: A language and environment for statistical computing. R Foundation for Statistical Computing, Vienna, Austria. http://www.R-project.org/

Rice A, Glick L, Abadi S, Einhorn M, Kopelman NM, Salman-Minkov A, Mayzel J, Chay O, Mayrose I (2014) The Chromosome Counts Database (CCDB) - a community resource of plant chromosome numbers. New Phytologist http://ccdb.tau.ac.il/ [accessed 24 January 2015]

Ross L, Blackmon H, Lorite P, Gokhman VE, Hardy NB (2015) Recombination, chromosome number and eusociality in the Hymenoptera. Journal of Evolutionary Biology 28: 105-116. https://doi.org/10.1111/jeb.12543

Rössler Y, DeBach P (1973) Genetic variability in a thelytokous form of Aphytis mytilaspidis (LeBaron) (Hymenoptera: Aphelinidae). Hilgardia 42: 149-175. https://doi.org/10.3733/ hilg.v42n05p149

Sharakhova MV, George P, Timoshevskiy V, Sharma A, Peery A, Sharakhov IV (2014) Mosquitoes (Diptera). In: Sharakhov IV (Ed.) Protocols for cytogenetic mapping of arthropod genomes. CRC Press, Boca Raton, Florida, 93-170. https://doi.org/10.1201/b17450-5

Timberlake PH (1924) Descriptions of new Chalcid-flies from Hawaii and Mexico (Hymenoptera). Proceedings of the Hawaiian Entomological Society 5: 395-417.

Vergilino R, Dionne K, Nozais C, Dufresne F, Belzile C (2012) Genome size differences in Hyalella cryptic species. Genome 55: 134-139. https://doi.org/10.1139/g11-085

Viggiani G (1967) Richerche sugli Hymenoptera Chalcidoidea. XV. Osservazioni cariologiche preliminari sull'Aphelinus mali (Hald.). Bolletino del Laboratorio di Entomologia Agraria "Filippo Silvestri" 25: 326-330.

White MJD (1973) Animal Cytology and Evolution. Cambridge University Press, Cambridge, $961 \mathrm{pp}$.

Yasnosh VA (1963) New species of the genus Aphelinus Dalm. (Hymenoptera, Chalcidoidea) in the fauna of the USSR. Entomological Review 42: 178-189.

Zehavi A, Rosen D (1988) A new species of Aphelinus (Hymenoptera: Aphelinidae) from Israel, with notes on the mali group. Israel Journal of Entomology 22: 101-108. 